\title{
МЕТАФИЗИЧЕСКИЙ ХАРАКТЕР ВОЙНЫ В КОНЦЕПЦИЯХ Э. ЮНГЕРА И Я. ПАТОЧКИ
}

\section{И.Н. Сидоренко}

В конце XIX - начале XX веков в философии актуализировалась проблема войны и насилия. Во многом это было связано с социальнополитическим и экономическим кризисом, с Первой мировой войной и революцией. Современный мир начала XXI столетия также ввергнут в состояние кризиса, его сотрясают войны и революции. Существенное отличие этих эпох заключается в том, что войны конца XX начала XXI вв. приобретают глобальный характер, а приватизация насилия приводит к его эскалации в так называемых «нетрадиционных войнах». Представление о том, что мир является causa finalis военного столкновения двух держав, определял все войны, которые велись в системе монархических государств вплоть до XX века. Причины и особенности ведения этих войн предполагали их частный характер, то есть война представляла собой не отрицание, а, наоборот, подтверждение мира. Окончание войн подразумевало обеспечение мира, что, в итоге, изначально наделяло войну возможностью быть рационализированной и иметь «нравственное» оправдание. Однако Первая мировая война утрачивает эту возможность вместе с утратой частного характера, что свидетельствует о стирании границ между войной и миром, и, собственно, о трансформации войны. В силу этого, сегодня возникает необходимость в философском осмыслении сущности насилия и обращении к философским концепциям войны.

Немецкий мыслитель Эрнст Юнгер и чешский философ Ян Паточка, каждый по-своему и в свое время, ставят задачу разъяснить природу войн XX века. Так, в концепции «тотальной мобилизации» Юнгера и в экзистенциально-феноменологической философии Паточки война 
приобретает метафизический характер, определяющий, в свою очередь, всю «ткань» социальной реальности. В современном мире война из средства политики превращается в саму политику, из средства достижения мира - в сам мир, из ограниченных во времени и пространстве военных конфликтов - в тотальную войну. Существенные изменения, связанные с трансформацией современной войны, состоят в том, что война из преступления превращается в полицейскую акцию; разрозненные проявления терроризма трансформируются в глобальный терроризм; происходит размывание границ национальных государств, что, в свою очередь, лишает их права на национальный суверенитет; регулярная война, основанная на принципах Публичного европейского права, превращается в новую «справедливую войну», стремящуюся к тотальности. Поэтому обоснована и справедлива интерпретация Юнгером и Паточкой Первой мировой войны как события, радикально определившего исторические черты новой эпохи, ознаменовавшего поворот, смену эпох.

Прежде всего, стоит отметить, что Юнгер определяет войну как символическое проявление бытия, как тотальность, объединяющую в себе как зло, так и добро, как ночь, так и день. В силу этого он наделяет войну метафизическим характером, который есть не что иное, как тотальная мобилизация, выступающая в форме технической революции (см.: [3]). Первая мировая война стала «общей судьбой», позволившей объединить разобщенное общество бюргеров, именно в этом проявилась ее «новизна» и метафизический характер. Мировая война, разрушая ложную индивидуальность бюргера, предстала перед Юнгером как некая творческая сила, способная объединить и сделать всех равными. Ссылаясь на Юнгера, Эрик Лид указывает, что именно на войне оборона Германии была обороной от бюргерства как социального атомизма, торгашества, аналитического разума и договорных общественных отношений, вопроизводящих эксплуатацию, всего того, что было характерно для коммерциализированной Англии [4, с. 59].

Так война стала символом отказа от ложной индивидуальности бюргера, от разобщающей частной жизни, от социального хаоса, от противоречий общества модерна. Вот как об этом пишет Ханна Арендт:

Фронтовое поколение, в заметном отличии от избранных ими духовных отцов, было совершенно захвачено желанием увидеть гибель всего этого мира фальшивой безопасности, поддельной культуры и притворной жизни $[1$, с. 436$]$.

Не удивительно, что Юнгер воспринял Первую мировую войну как 
ключевое событие в жизни своего поколения: в этой битве массы и машины разрушились прежние устои, и произошла глубокая трансформация личности и общества. Человек перестал быть значимой величиной в этой войне, которая предстала как мощь самопреобразующегося бытия, став мистическим столкновением природных сил, вызвавшим шоковое состояние. Именно поэтому в событии войны немецкий мыслитель открывает огромный революционный потенциал: благодаря осмыслению войны как космического феномена жизни, примиряющего и объединяющего в себе дневную и ночную стороны, он фиксирует переход войны из частичного состояния в состояние тотальное. Сущность войны - это работа, то есть степень вооружения. В силу этого, метафизический характер новой войны проявляется уже не в битвах армий солдат, а в битве армий рабочих. В результате происходит размывание границ между миром и войной, так как уже невозможно различить работу в мирных целях и работу в целях войны. Отсюда тотальность, присущая новой войне ХХ столетия, сама становится миром. Стирается граница между солдатом и рабочим, их уже нельзя различить: солдат стал рабочим в гигантском техническом аппарате, а рабочий трансформировался в солдата, чья деятельность теперь подчинена только войне.

Вслед за Юнгером, Паточка также истолковывает мировую войну через открытие феномена ночи, отмечая при этом, что величайший опыт фронта и пребывания на линии огня заключается именно в том, что он заставил увидеть ночь и уже не позволяет забыть о ней $[2$, c. 155]. Несмотря на то, что с позиции дня жизнь представляет собой высшую ценность, которая правит человеком через требование избегать опасности смерти, на фронте она уступает место жертве, в которой обнаруживается свобода от всех интересов мира, жизни и дня, поскольку от тех, кто «приносится в жертву, требуется лишь выдержка перед лицом смерти». Таким образом, самое глубокое открытие фронта, - подчеркивает Паточка, - состоит в переживании «обрыва жизни в ночь, борьбу и смерть, осознание, что их нельзя списать со счетов жизни, хотя с точки зрения дня они кажутся просто небытием» [там же, с. 151]. Риторика XX века как «эпоха ночи, войны и смерти» не может быть описана в терминах XIX века. Являясь, согласно Паточке, следствием «онаучивания», война, тем не менее, не поддается рационализации, поскольку не имеет смысла в себе самой. Что же означает его утверждение о том, что вторая мировая война не закончилась, а перешла в странное состояние «ни войны, ни мира»? Используя его определение войны через феномен ночи, можно ответить так: мир властвует 
над человеком через угрозу смерти, а воля к войне ориентируется на будущие поколения, то есть на мир. Таким образом, война сопутствует миру, закрывающему глаза на смерть.

Юнгер, раскрывая метафизический характер мировой войны, полагал, что смысл войны может быть раскрыт только исходя из смысла самой истории. Так, тотальная мобилизация, проявившаяся в Первой мировой войне, предстает у Юнгера как характеристика современной эпохи, суть и цель которой заключаются в вооружении. Эту современную эпоху он определяет как «эпоху работы». Именно поэтому Первая мировая война становится небывалым историческим событием, по своей значимости превосходящим Французскую революцию. Война превращается в гигантский механизм, «фабрику», которая одновременно производит и потребляет энергию. Для того, чтобы выдержать в этой войне, государству недостаточно просто вооружиться; вооружение должно «проникнуть до мозга костей», стать сутью жизни общества и человека как проявления типического, как Рабочего.

Эту задачу принимает на себя тотальная мобилизация, акт, посредством которого широко разветвленная и сплетенная из многочисленных артерий сеть современной жизни одним движением рубильника подключается к обильному потоку военной энергии [3, с. 449-450].

K поиску смысла войны обращается и Паточка. Различие между войнами он видит в их идейности. Войны всегда проходили на фоне всеобщего убеждения в наличии позитивной идеи, например, идеи о том, что разум управляет миром. Что же касается войн $\mathrm{XX}$ века, то их питает идея о том, что не существует никакого вечного объективного смысла мира и вещей и что смысл можно установить только посредством силы. Первая мировая война определила весь характер XX столетия, прежде всего показав, что

преобразование мира в лабораторию, где актуализируются запасы энергии, аккумулированные на протяжении миллиардов лет, должно осуществляться именно посредством войны. Поэтому война имела значение определяющего прорыва в том понимании сущего, исток которого принадлежит XVII в. и которое связано с возникновением механистического естествознания, с отстранением всех «конвенций», стоящих на пути этого высвобождения силы, - путем переоценки всех ценностей под знаком силы [2, с. 154].

В силу этого энергетическое преобразование мира должно происходить посредством войны потому, что война, как крайняя форма столкновения, является самым интенсивным средством быстрого высвобождения аккумулированных сил. 
Конфликт - это великое средство, которым, выражаясь мифологически, воспользовалась Сила для перехода из потенциального в актуальное состояние [там же].

В свою очередь Юнгер, видя в Первой мировой войне симптом новой эпохи, отсвет нового мира, приходит к выводу о том, что есть три причины этого процесса осуществления новой эпохи: во-первых, это человеческая ненависть и вражда, во-вторых, это застой и омертвление расы, в-третьих, это механизация и варваризация Европы (см.: [3]). Начнем с первой причины войны как главного симптома новой эпохи. Юнгер полагает, что враждебность и насилие укоренены в природе человека, который был создан «бюргерской эпохой», базирующейся на ценностях и идеалах духа Просвещения. Результатом бюргерского «разумно-добродетельного образа мира», с точки зрения Юнгера, является господство ловкого дельца, который все измеряет экономическими категориями. Экономика же, по мысли немецкого философа, не есть та власть, которая может предоставить свободу, поэтому «высший закон борьбы» главенствует и над экономикой. Война символизирует приход нового четвертого сословия, отождествляемого с рабочим. Рабочее сословие выступает против общества как сферы «общественного договора», и сутью восстания рабочего становится не экономическая свобода, которая есть лишь иллюзия, и не экономическая власть, а власть вообще и подлинная свобода духа. Для этого недостаточно одной только борьбы за свободу, необходима ломка всей системы. В силу этого, война предстает не просто как некое действие, а как священное действие, очищающее и преобразующее мир.

Вторая причина Первой мировой войны, которую выделяет Юнгер, - это болезнь расы. Здесь необходимо отметить, что войну как борьбу народов философ не связывает с достижением справедливости, напротив, он ее рассматривает как борьбу за бытие, за творческую силу народа. В такой борьбе нет однозначно правых и виноватых, а значит, война может быть оправдана с двух сторон. На первый взгляд, кажется, что Юнгер становится на позицию нравственного индифферентизма, однако это не так. Война рассматривается ним как средство преобразования массы индивидов в единый тип. Задачу нации, так же как и единичного человека, он видит в том, чтобы отказаться от индивидуального образца и постичь себя как представителя гештальта рабочего. Рабочий - это принципиально иной социальный тип, который формирует общество нового типа, в котором война и труд, будучи тождественны, размывают социальные границы. Отсюда цель народа-это не благополучие, а героическое и трагическое переживание 
народом своей исторической судьбы. Поэтому правомерность войны заключается в том, что она преодолевает раздробленность нации и деструкцию мира: зло разделяет и разобщает, война объединяет и делает целостным.

Симптом новой эпохи, проявившийся в Первой мировой войне, имеет и третью причину: это механизация и варваризация Европы. Существование Европы перед мировой войной мирным назвать нельзя: за ее иллюзорным миром скрывалась вражда и ненависть, ее мир охранялся только угрозой войны. Однако технизация Первой мировой войны только усугубила силы милитаризма под видом «футуристической техники». Понимание войны как тотальности позволило Юнгеру увидеть в технической революции современности скрытый «военный потенциал», выражающийся в том, что техника, обнажая свой военный характер, одновременно выдает свою связь с жизнью, является «инструментом жизни». Так, военный потенциал техники открывает возможность для преобразования мира, смены эпох. Первая мировая война принесла не только смерть, ужас и страдания, она проявила не только онтологическое зло, но и сделала явным роковой процесс машинизации жизни, замену органической жизни механической. Таким образом, в эпоху масс и машин образ войны вписывается в повседневную жизнь, становится составляющей мира. При этом, как отмечает Паточка, продолжая развивать эту идею Юнгера, силы дня, которые на протяжении XX века посылали миллионы людей в огненную геенну войны, не умирают, а только исчерпываются, и им все равно, уничтожать или организовывать массы [2, с. 150-151].

Паточка, раскрывая метафизическую природу войны, прослеживает ее экзистенциальные аспекты. Он обращается к описанию фронтового опыта Юнгера, испытавшего потрясение фронта, которое можно определить не просто как травму, а как основополагающее изменение в человеческом существовании. Несомненно, война как фронт, отмечает человека навсегда, проявляя экзистенциальный ужас, отличный от страха, боязни. Подчеркнем, что у Паточки не идет речь о военной романтике и притягательности гибели, «то, что овладевает человеком на фронте, - это подавляющее все чувства ощущение смысловой полноты, которую, однако, трудно выразить с помощью слов» [там же, с. 155-156]. Паточка, анализируя фронтовой опыт, выделяет в его переживании несколько фаз.

Первая фаза - это переживание бессмысленности, абсурдности фронта и невыносимого ужаса. Осмысленным здесь остается только мысль о том, что мир, порождающий нечто подобное, должен 
исчезнуть. В силу этого, второй фазой становится активное неприятие, которое выдается как борьба за мир. Ее следствием становится то, что едва столкнувшись с потрясением мира, человек вновь «захватывается» силами мира, мобилизируясь для новой борьбы. Так, бессмысленность прежней жизни и войны учреждает смысл новой войны, войны против войны. Победа в такой войне является лишь видимостью, благодаря которой приготовляется будущее поражение, а поражение приводит к возникновению новых битв. То, что действительно побеждает в этой борьбе, - это сила, использующая мир как средство войны. Так мир становится составной частью войны. Именно поэтому, отмечает Паточка, Германия оказалась способной к повторению драмы 1914 года, т. е. способной ни к чему иному, как к повтору, сопровождаемому еще более бессмысленной военной машинерией, более изощренными актами насилия, мести и ressentiment. C точки зрения Паточки, мир, жизнь, день властвуют над человеком при помощи смерти и угрозы для жизни [там же, с. 149]. В воле к войне, таким образом, господствуют день и жизнь, использующие смерть. Воля к войне рассчитывает на будущие поколения, а значит, в ней господствует мир. Таким образом, от войны невозможно избавиться, поскольку, вооружаясь для защиты мира и тем самым подчиняясь господству жизни, мы обрекаем себя на войну.

Что касается третьей фазы переживания опыта фронта, то она связана с тем, что этот опыт взывает к ночи, даря абсолютную свободу. Мир, во имя которого мы ведем войны, господствует, посылая одних на смерть для того, чтобы у других был завтрашний день. Как уже было отмечено, от тех же, кого приносят в жертву, требуется выдержка перед лицом смерти. Наступает понимание того, что жизнь - это не все, от нее самой можно отказаться. С позиции мира и дня именно этот отказ и требуется. Опыт же фронта - это абсолютный опыт, дающий возможность постигнуть абсолютную свободу, «свободу от всех интересов мира, дня и жизни». Это означает, по мысли Паточки, что

жертва этих обреченных теряет относительное значение, перестает служить путем к программам восстановления, прогресса и расширения жизненных возможностей и получает значение исключительно в себе самой [там же, с. 160].

Оказаться способным к такой свободе, быть призванным в мир, который посредством конфликта мобилизует силу, это значит одновременно преодолеть эту силу, суметь противостоять миру, ставшему волей к войне и опредметившему человека, «вывернув его наизнанку». 
Так ночь внезапно становится абсолютным препятствием на пути к дурной бесконечности завтрашнего дня [там же, с. 161].

Ночь, если следовать мысли Паточки, раскрывает предельную возможность для жертвы провозгласить себя в качестве «истинной надындивидуальности». Враг перестает быть абсолютным противником, он становится соучастником постижения опыта абсолютной свободы, тем, с кем возможно «согласие в разногласии». Именно так, согласно мысли чешского философа, проявляется солидарность потрясенных вопреки противостоянию. Четвертой, и последней, фазой становится открытие наличия жизни в ночи, в смерти, преобразование жизненного смысла на границе с Ничто, что в итоге приводит к пониманию того, что именно сама жизнь и порождает войну, а война как средство силы, служащее ее высвобождению, не может закончиться сама собой. Паточка сожалеет, что опыт абсолютной свободы, объединивший врагов в акте солидарности, не нашел применения в истории XX века, породившей такой феномен как «война против войны» [там же, с. 156-157].

Если Паточка актуализирует экзистенциальный аспект войны, то Юнгер акцентирует проблему правового обеспечения войны, видя в ней не способ остановить войну, а средство камуфлирования войны под мирное вторжение, санкционирования de jure уже свершившихся de facto актов насилия. Законы не могут сдержать войны и насилие, человечество еще не создало «механизма», который бы остановил и покончил с милитаризмом, а значит, война еще не выполнила полностью свою онтологическую миссию - закалку и победу духа в борьбе со злом. В силу этого, механизация войны, ее техническое усовершенствование может стать стимулом к преодолению самой возможности войны как тотального уничтожения жизни.

Однако Первая мировая война не стала победой духа, а закончилась «дурным миром», то есть внутренним продолжением войны, вылившимся в трагедию Второй мировой войны. Тоталитаризм техники и варваризация цивилизации, симптоматику которых описали, каждый по своему, Юнгер и Паточка, обернулись не победой духа, а возникновением новых «нетрадиционных войн», сущность которых заключается в том, что одновременно имеют место и война, и мир; происходят как преступления, так и боевые действия, страдают как гражданские лица, так и солдаты. Новая «нетрадиционная» война ведется не в национальных интересах, напротив, она снимает ограничение ответственности государств национальной территорией, превращаясь в 
своеобразные «мировые полицейские войны», утверждающие не «подлинное единство нации» в понимании Юнгера или «опыт солидарности» Паточки, а политику военизированного гуманизма, приводящую к эскалации насилия. Таким образом, вывод очевиден и печален: размах социально-экономического кризиса, нищета в странах «третьего мира», военные конфликты и терроризм доказывают неспособность человека глобализирующегося мира победить в войне, которая понимается как «борьба за мир», ведь условием возможности мира уже давно стала война, а мир уже давно перестал быть мирным. Паточка видит только один выход из сложившейся ситуации - это реализация солидарности потрясенных, тех, кто понимает и не остается равнодушным, и в чьих руках, поэтому, потенциально находятся все силы. В силу этого солидарность потрясенных может противостоять всем тем мобилизационным мероприятиям, делающим состояние войны непрерывным.

\section{Литература}

[1] Арендm Х. Истоки тоталитаризма.-М. : ЦентрКом, 1996.

[2] Паточка Я. Еретические эссе о философии истории.-Минск: И.П. Логвинов, 2008.

[3] Юнгер Э. Рабочий. Господство и гештальт; Тотальная мобилизация; О боли. - СПб. : Наука, 2002.

[4] Leed E. No man's land. Combat \& identity in World War I. Cambridge, London, New York, Melbourne: Cambridge University Press, 1979.

Надійшла до редакиї̈ 10 червня 2016 р. 


\section{Анотація}

Полякова В.О. Архітектура пам’яті у творах Готфрида Лейбніца в перспективі сучасних досліджень

У статті автор розглядає окремі характеристики пам’яті, її місце в структурі особистості, зв’язок між пам'яттю і досвідом як їх розуміє Лейбніц. Акцентується увага на тих аспектах лейбніцевської концепції пам'яті, що знаходять подальший розвиток у сучасній науковій літературі.

Ключові слова: Лейбніц, пам’ять, спогад, простір, сприйняття.

\section{Abstract}

Polyakova V.O. An architecture of memory in the work by Gottfried Leibniz from a standpoint of modern investigations

The author investigates some aspects of Leibniz's conception of memory, interconnections between memory and experience and the place of memory in the structure of person. The paper contains an overview of the philosophical heritage of Leibniz as presented in the modern scientific literature.

Keywords: Leibnitz; memory; reminiscence; space; perception

\section{References}

1. Arnhejm R. Iskusstvo i vizualnoe vospriyatie. - Moscow : Progress, 1974.

2. Bayuk D.A., Fedorova O.B. Lejbnic v Rossii: perevody i ih avtory // Voprosy istorii estestvoznaniya i tekhniki. — 2014. — № 2. — S. 3-24.

3. Bachelard G. Izbrannoe: Poehtika prostranstva. - Moscow : ROSSPEN, 2004.

4. Behddeli A. Vasha pamyat. Rukovodstvo po trenirovke i razvitiyu. Moscow : EHKSMO-PRESS, 2001.

5. Kaneman D. Dumaj medlenno. . . reshaj bystro. — Moscow : AST, 2014.

6. Leibniz G.W. Sochineniya v chetyrekh tomah. - Moscow : Mysl, 1982-89 gg. - t. 1 ; t. 2 ; t. 3 ; t. 4 . 
7. Maklyuen M. Galaktika Gutenberga: Sotvorenie cheloveka pechatnoj kultury. — Kyiv : Nika-Centr, 2004.

8. Malyshkin E.V. Dve metafory pamyati. — SPb. : Izdatelskij dom SanktPeterburgskogo gosudarstvennogo universiteta, 2011.

9. Najsser U. Poznanie i realnost. — Moscow : Progress, 1981.

10. Sekundant S.G. Epistemologiya Lejbnica v ee normativno-kriticheskih osnovaniyah [monografiya]. — Odessa : Pechatnyj dom, 2013.

11. Shevcov K. Pamyat monad v sisteme «predustanovlennoj garmonii» // Sententiae. — 2012. — № 2. — S. 29-45.

12. Bobro M.E. Self and Substance in Leibniz. — Dordrecht, Boston, London: Kluwer Academic Publishers. — 2004. — VII.

13. Kandel E.R. In Search of Memory: The Emergence of a New Science of Mind. — New York : W.W. Norton \& Company, 2006.

14. Murty V.P., LaBar K.S., Hamilton D.A., Adcock R.A. Is all motivation good for learning: Dissociable influences of approach and avoidance motivation in declarative memory // Learning and Memory. — 2011. — № 18. — P. 712717. 